Article

\title{
Evaluation of Orthorexia Nervosa and Symptomatology Associated with Eating Disorders among European University Students: A Multicentre Cross-Sectional Study
}

\author{
Anna Brytek-Matera ${ }^{1, *(1)}$, María Dolores Onieva-Zafra ${ }^{2}(0)$, María Laura Parra-Fernández ${ }^{2}(\mathbb{0}$, \\ Anna Staniszewska ${ }^{3}$, Justyna Modrzejewska ${ }^{4}$ and Elia Fernández-Martínez ${ }^{5}$ (D) \\ 1 Institute of Psychology, University of Wroclaw, 50-527 Wroclaw, Poland \\ 2 Department of Nursing, Physiotherapy and Occupational Therapy, Faculty of Nursing of Ciudad Real, \\ Universidad de Castilla-La Mancha, 13071 Ciudad Real, Spain; mariadolores.onieva@uclm.es (M.D.O.-Z.); \\ marialaura.parra@uclm.es (M.L.P.-F.) \\ 3 Department of Experimental and Clinical Pharmacology, Medical University of Warsaw, \\ 02-091 Warsaw, Poland; astaniszewska@wum.edu.pl \\ 4 Institute of Pedagogy, Faculty of Humanities and Social Sciences, University of Bielsko-Biała, \\ 43-310 Bielsko-Biała, Poland; justyna.modrzejewska@wp.pl \\ 5 Department of Nursing, University of Huelva, 21071 Huelva, Spain; elia.fernandez@denf.uhu.es \\ * Correspondence: anna.brytek-matera@uwr.edu.pl
}

Received: 7 November 2020; Accepted: 30 November 2020; Published: 1 December 2020

\begin{abstract}
The objectives of the present study were to (1) evaluate prevalence of orthorexia nervosa $(\mathrm{ON})$ in university students in Spain and Poland, (2) assess differences in ON and eating disorder (ED) pathology in both samples and (3) examine the relationship between ON and ED symptoms among Spanish and Polish university students. Eight hundred and sixty university students participated in the present study $\left(M_{\mathrm{age}}=21.17 \pm 3.38 ; M_{\mathrm{BMI}}=22.57 \pm 3.76\right)$. The Spanish and Polish samples comprised 485 and 375 students, respectively. The Düsseldorf Orthorexia Scale and the Eating Disorder Inventory were used in the present study. ON prevalence rates of $2.3 \%$ and $2.9 \%$, respectively, are found in the Spanish and Polish samples. Compared to Polish students, Spanish university students reported increased drive for thinness and lower body dissatisfaction, lower level of ineffectiveness and lower level of interpersonal distrust. ON was positively related to drive for thinness, bulimia, body dissatisfaction, perfectionism interoceptive awareness (in both Spanish and Polish students) and ineffectiveness (in Spanish students). Our findings suggest that ON significantly overlaps with ED symptoms, which is in line with recent studies. Longitudinal studies are needed to assess how ON develops in a sample of young adults and whether it develops in isolation of or in parallel with ED pathology.
\end{abstract}

Keywords: orthorexia nervosa; eating disorder pathology; cross-cultural study; university students

\section{Introduction}

Eating behaviour is strongly influenced by social context [1]. Over the last several years societal attitudes towards healthy eating and dietary behaviour are changing, with an increasing emphasis on high-quality foods or 'clean' eating [2]. "Clean eating" (restrictive eating patterns focusing on the consumption of healthy, "pure" foods) may reflect vulnerability to a pathological fixation with healthy eating [3]. Orthorexia nervosa $(\mathrm{ON})[4,5]$ is characterised by an obsessive focus on "healthy" or "pure" eating, strict avoidance of foods considered to be impure, unhealthy or improper, intense preoccupation 
regarding dietary practices, and very rigid dietary rules with violations causing exaggerated emotional distress [6]. Restrictive diet is not used for weight-loss purposes but is related to the pursuit of health. Preoccupation with either affirmative or restrictive dietary practices believed to promote health (which result in the exclusion of entire food groups), focus on food quality (not quantity), self-punishment when not complying with dietary rules, health complications (e.g., malnutrition), psychological disturbances (e.g., major depressive disorder [7]), and cognitive distortions [8] are features of ON [9].

Recently, Barrada and Roncero [10] described two differentiable dimensions in diet preoccupation, one associated with the pathological dimension of $\mathrm{ON}(\mathrm{OrNe})$ and the other connected to a nonpathological interest in healthy eating (healthy orthorexia; HeOr). OrNe evaluates the negative social and emotional impact of trying to achieve a rigid way of eating. This dimension represents a pathological preoccupation with a healthy diet, which leads to negative consequences such as self-punishment, social isolation, and guilt, whereas HeOr assesses the tendency to have a healthy, balanced diet and interest in doing so. HeOr represents a healthy interest with diet, which is independent of psychopathology (eating disorders, obsessive-compulsive disorder, and negative affect). In this context, ON may be considered as adaptive due to selective healthy eating and its social characteristics (orthorexic behaviours are relevant evolutionary strategies because they can enable earning recognition and honours from others [11]). Therefore, $\mathrm{ON}$ may be viewed (tentatively) as a healthy diet protecting one's health but also as a phenomenon having negative influence on health [12], however, this viewpoint should be adopted with some caution, due to the limited number of available studies on these subjects, and should hence be further tested in the future studies.

The prevalence of $\mathrm{ON}$ has been evaluated with considerable inconsistency mainly due to the employment of the different tools for evaluating the same construct. Depending on the population being studied (e.g., university students, athletes, patients with eating disorders) and the instrument being used (ORTO-15) rates between 1\% and 90\% have been reported [13]. While the ORTO-15 [14] has, to date, been the most widely used questionnaire, the Düsseldorf Orthorexia Scale (DOS) [15] was recently implemented to assess the prevalence of ON. Assessments via DOS have found cross-sectional rates for $\mathrm{ON}$ between $1.5 \%$ [16] and $6.9 \%$ in the general population [17] and between 3.3\% [18] and $10.5 \%[19,20]$ among university students (Table 1). 
Table 1. Studies assessing orthorexia nervosa (ON) using the Düsseldorf Orthorexia Scale (DOS) among a sample of university students.

\begin{tabular}{|c|c|c|c|c|c|c|}
\hline \multirow[b]{2}{*}{ Authors } & \multirow{2}{*}{ Country } & \multirow{2}{*}{$\mathbf{N}$} & \multirow[b]{2}{*}{ Gender } & \multirow{2}{*}{ Age } & $\begin{array}{l}\text { Prevalence of ON (\%) Based } \\
\text { on DOS across All Sample }\end{array}$ & $\begin{array}{l}\text { Prevalence of ON }(\%) \text { Based } \\
\text { on DOS across Gender }\end{array}$ \\
\hline & & & & & \multicolumn{2}{|c|}{$\begin{array}{l}\text { a. Presence of ON }(\geq 30) \\
\text { b. At Risk of ON }(25-29) \\
\text { c. No Risk of ON }(<25)\end{array}$} \\
\hline Depa et al. [18] & Germany & 446 & $\begin{array}{l}70 \% \text { female } \\
30 \% \text { male }\end{array}$ & $21.7 \pm 2.6$ & $\begin{array}{l}\text { a. } 3.3 \% \\
\text { b. } 9.0 \% \\
\text { c. } 87.7 \%\end{array}$ & $\begin{array}{c}\text { 1. } 2.8 \% \text { female } \\
3.7 \% \text { male } \\
\text { 2. } 10.4 \% \text { female } 5.9 \% \text { male } \\
\text { 3. na }\end{array}$ \\
\hline Chard et al. [21] & $\begin{array}{l}\text { United States of } \\
\text { America }\end{array}$ & 384 & $\begin{array}{l}69.5 \% \text { female } \\
30.5 \% \text { male }\end{array}$ & $19.64 \pm 2.58$ & $\begin{array}{l}\text { a. } 8 \% \\
\text { b. } 12.4 \% \\
\text { c. } 79.5 \%\end{array}$ & na \\
\hline He et al. [22] & China & 1075 & $\begin{array}{l}52.7 \% \text { female } \\
47.3 \% \text { male }\end{array}$ & $20.11 \pm 1.01$ & $\begin{array}{l}\text { a. } 7.8 \% \\
\text { b. } 18.2 \% \\
\text { c. }\end{array}$ & $\begin{array}{l}\text { a. } 5.3 \% \text { female } \\
10.6 \% \text { male } \\
\text { b. } 14.5 \% \text { female } \\
22.4 \% \text { male }\end{array}$ \\
\hline $\begin{array}{l}\text { Parra-Fernández et al. } \\
\qquad[19,20]\end{array}$ & Spain & 492 & $\begin{array}{l}56.9 \% \text { female } \\
43.1 \% \text { male }\end{array}$ & $19.97 \pm 3.03$ & $\begin{array}{l}\text { a. } 10.5 \% \\
\text { b. na } \\
\text { c. } 89.4 \%\end{array}$ & $\begin{array}{c}\text { a. } 6.5 \% \text { female } \\
4.1 \% \text { male } \\
\text { b. na } \\
\text { c. } 93.5 \% \text { female } \\
95.9 \% \text { male }\end{array}$ \\
\hline Brytek-Matera, [23] & Poland & 412 & $\begin{array}{l}77.2 \% \text { female } \\
22.8 \% \text { male }\end{array}$ & $24.62 \pm 6.86$ & $\begin{array}{l}\text { a. } 6.6 \% \\
\text { b. } 11.9 \% \\
\text { c. } 81.5 \%\end{array}$ & $\begin{array}{c}\text { a. } 6.3 \% \text { female } \\
7.4 \% \text { male } \\
\text { b. } 12.6 \% \text { female } \\
9.6 \% \text { male } \\
\text { c. } 79.3 \% \text { female } \\
83 \% \text { male }\end{array}$ \\
\hline
\end{tabular}


Although in the past two decades interest in $\mathrm{ON}$ has increased, at present there exists ongoing debate on whether to consider $\mathrm{ON}$ as a single syndrome, a variance of an eating disorder (ED)—an antecedent of anorexia nervosa (AN), a way to maintain AN or a consequence of AN-or obsessive-compulsive disorder [24-26], a new variant of eating behaviour [27] or merely a culturally influenced attitude rather than a disease [28]. Previous studies have found a behavioural and symptomatology overlap between ON and AN $[10,29,30]$ and association between ON and disordered eating behaviours and attitudes toward food [6,31-33]. The major discrepancy between $\mathrm{ON}$ and AN occurs in the main goal: being healthy (preoccupation with consuming healthy and pure foods) versus weight loss (preoccupation with weight loss). In addition, $\mathrm{ON}$ is related to obsession about quality of food intake, whereas AN is associated with obsession about the quantity of food intake [34]. Food and eating preoccupation, dietary restrictions, making eating-related issues the primary focus of one's own life, intense anxiety regarding certain foods and their avoidance, sense of superiority over others based on one's own eating practices, need for control, obsessive-compulsive personality traits (e.g., perfectionism, rigidity) and ego-syntonic nature are common features for both ON and AN [35]. Moreover, neurocognitive deficits (impairments in set-shifting, external attention, working memory) [25,36], cognitive distortion (e.g., magical beliefs about food) as well as similar symptomatology are similar in $\mathrm{ON}$ and AN patients, which may indicate analogous brain dysfunction in these individuals [37].

Both eating habits (e.g., avoidance of certain type of foods as saturated fats or animal fat products, following a strict eating schedule, spending large amounts of time preparing meals) and disordered eating habits are related to greater ON [26]. Promoting a healthy diet and acquisition of healthy eating habits in young adults is an important challenge because of dietary pattern changes (breakfast skipping, eating outside home) and nonadherence of dietary guidelines (despite positive attitudes towards them) [38]. Since eating habits formed in young adulthood (study period) shape eating behaviours during later life [39] and eating attitudes and behaviours constitute a common health problem among university students, there is a need for more comprehensive studies to determine the nature of ON (and to identify ways of overcoming it). Nowadays there is limited evidence on the relationship between ON (measured by DOS) and ED symptoms among university students. Although the influence of cultural differences on has been discussed (see the recent review by Strahler [13]), the interaction between sociocultural context and $\mathrm{ON}$ has been poorly examined. Previous study has shown that higher nutrition knowledge and higher education levels are positively associated with the Mediterranean dietary pattern [40,41]. In addition, research on food choice has found that Southern European populations give greater importance to sociability and cooking and enjoying food with others [42]. Cross-cultural studies have suggested that populations that prioritize pleasure over health demonstrate healthier eating behaviours [42,43]. One might expect that the Mediterranean diet together with convivial and social value attributed to eating [40] may play an important role in the Spanish sample.

The present study aimed to (1) evaluate ON prevalence (as measured by the DOS) in university students in Spain and Poland, (2) assess differences in ED symptoms (measured with the EDI) in both samples and (3) examine the relationship between ON and ED symptoms among Spanish and Polish university students. Based on the recent study conducted among Italian, Polish and Spanish university students [40] (to our knowledge, the only study of its kind available in the literature), we hypothesize that:

Hypothesis 1 (H1). ON prevalence will be higher among Polish students than Spanish ones.

Hypothesis 2 (H2). Symptoms related to ED will be higher among university students in Poland than those in Spain.

Hypothesis 3 (H3). A relationship between ON and ED symptoms will exist in both Spanish and Polish students. 


\section{Materials and Methods}

\subsection{Study Design}

A multicentre cross-sectional study was performed to analyse the ON construct and ED symptoms in a sample of European university students from Spain and Poland. For this purpose, a convenience sample was recruited, based on a joint collaboration between both countries. Firstly, each of the authors proposed the research protocol to the students attending their university classes (different types of university degrees were involved, as detailed below, thus ensuring a wider representation of the university population). The participants were evaluated using a protocol that included informed consent, demographic and anamnestic data collection sheets, and self-administered questionnaires.

\subsection{Sample}

A descriptive cross-sectional study was carried out. In total, 485 students ( $>18$ years old) from the University of Castilla-La Mancha and 375 students ( $>18$ years old) from two Polish universities were invited to participate in the study. The participants were recruited via informative talks delivered during university lectures in different faculties (nursing, law, chemistry, computer science and education in Spain and psychology, pedagogy, sociology in Poland). Enrolment in the study was voluntary and participants were requested to complete the online-survey developed using the JotForm platform (Spain) or through Google Forms (Poland). For ethical reasons, we were unable to inquire about the causes that led them to refuse to participate. The participants received no financial incentive. Written consent was obtained from the participants and the ethics committee of the University Hospital of Castilla-La Mancha (Code C-153) who approved the study according to the ethical guidelines outlined in the Declaration of Helsinki in 2013.

\subsection{Instruments}

\subsubsection{Demographic Information}

Demographic information was gathered, including participants' self-reported sociodemographic characteristics such as age, gender, variables such as weight and height. The average body mass index (BMI) was calculated based on the self-reported weight and height of participants.

\subsubsection{Düsseldorf Orthorexia Scale (DOS)}

The DOS [15] is a unidimensional measure for assessing and screening ON. It includes ten items. The answers are based on a four-point Likert scale where $1=$ never, $2=$ rarely, $3=$ often and $4=$ always. The score ranges from 10 to 40 points. The cut-off point is $\geq 30$ points for labelling the presence of ON. A score between 25 and 29 identifies a risk of developing ON, while a total score of less than 25 demonstrates the absence of $\mathrm{ON}$ [15]. The internal consistency of the original scale was 0.83 . This scale was validated in both Spanish and Polish and the psychometric properties were considered adequate. The internal consistency for the Spanish version of the DOS is 0.841 [19] and for the Polish version (DOS-PL) is 0.840 [23].

\subsubsection{Eating Disorder Inventory (EDI)}

The EDI [44] was designed to evaluate different cognitive and behavioural features of AN and bulimia nervosa (BN). The EDI consists of 64 items divided into eight subscales: drive for thinness, bulimia, body dissatisfaction, ineffectiveness, perfectionism, interpersonal distrust, interoceptive awareness and maturity fears. Each item is assessed according to a six-point scale (from "always" to "never") with a score of 0-3. All subscales can be added together for an overall score or each subscale can be used separately. Both Spanish [45] and Polish version of the EDI [46] shows a satisfactory internal consistency (Spanish version: $\alpha=0.65$ to 0.93; Polish version: $\alpha=0.65$ to 0.92 ). 


\subsection{Statistical Analysis}

A bivariate descriptive analysis was carried out with the sociodemographic and anthropometric data using frequencies and percentages for the qualitative variables and using mean and standard deviation for the quantitative variables comparing the samples of Spanish and Polish university students. The chi-square linear trend test was used to compare the qualitative variables with the BMI categorized as an ordinal variable. For the comparison of quantitative variables the Student's $t$-test was used for independent samples. A comparison of the scores of the eight dimensions of the EDI was carried out among the students of both countries also by means of this last statistical test. Finally, a Pearson's correlation was made between the DOS scores and the EDI dimensions in the samples from both countries and globally. The appropriateness of conditions for the application of the statistical tests employed was verified in all cases. The established significance level was 0.05 .

\section{Results}

\subsection{Sociodemographic and Anthropometric Results}

A total of 860 university students participated, of which $43.6 \%$ (375) were Polish and $56.4 \%$ (485) were Spanish, $65.1 \%$ (560) were women and 34.9\% (300) were men. The mean age of the total participants was $21.17 \pm 3.38$ (Min. 18-Max. 35) and their mean BMI was $22.57 \pm 3.76 \mathrm{~kg} / \mathrm{m}^{2}$. When categorized according to WHO references (WHO, 2000), 8.7\% (75) were underweight $\left(\leq 18.5 \mathrm{~kg} / \mathrm{m}^{2}\right), 71.2 \%(612)$ had normal weight $\left(18.5-24.99 \mathrm{~kg} / \mathrm{m}^{2}\right), 15.3 \%$ (132) were overweight $\left(25-29.99 \mathrm{~kg} / \mathrm{m}^{2}\right)$ and $4.8 \%(41)$ were obese $\left(\geq 30 \mathrm{~kg} / \mathrm{m}^{2}\right)$. The comparison of sociodemographic and anthropometric data between countries is shown in Table 2.

Table 2. Sociodemographic and anthropometric results in Spanish and Polish students.

\begin{tabular}{|c|c|c|c|c|c|c|c|c|}
\hline \multirow{2}{*}{\multicolumn{2}{|c|}{ Variables }} & \multicolumn{3}{|c|}{$\begin{array}{c}\text { Spain } \\
(n=485)\end{array}$} & \multicolumn{3}{|c|}{$\begin{array}{l}\text { Poland } \\
(n=375)\end{array}$} & \multirow[t]{2}{*}{$p$ Value } \\
\hline & & $\mathbf{n}$ & $\%$ & $\mathrm{M} \pm \mathrm{SD}$ & $\mathbf{n}$ & $\%$ & $\mathrm{M} \pm \mathrm{SD}$ & \\
\hline \multirow{2}{*}{ Sex } & Male & 210 & 43.3 & - & 90 & 24 & - & \multirow{2}{*}{$0.000^{a, * *}$} \\
\hline & Female & 275 & 56.7 & - & 285 & 76 & - & \\
\hline Age (years) & - & - & - & $19.76 \pm 2.18$ & - & - & $22.99 \pm 3.77$ & $0.000^{b, * *}$ \\
\hline $\mathrm{BMI}\left(\mathrm{kg} / \mathrm{m}^{2}\right)$ & - & - & - & $22.43 \pm 3.54$ & - & - & $22.76 \pm 4.03$ & $0.197^{b}$ \\
\hline \multirow{4}{*}{ BMI ranges } & $\leq 18.5$ & 47 & 9.7 & - & 28 & 7.5 & - & \multirow{4}{*}{$0.077^{c}$} \\
\hline & $18.5-24.99$ & 349 & 72 & - & 263 & 70.1 & - & \\
\hline & $25-29.99$ & 69 & 14.2 & - & 63 & 16.8 & - & \\
\hline & $\geq 30$ & 20 & 4.1 & - & 21 & 5.6 & - & \\
\hline
\end{tabular}

${ }^{\mathrm{a}}$ Chi-squared test, ${ }^{\mathrm{b}}$ Student's $t$-test; ${ }^{\mathrm{c}}$ chi-square linear trend test; ${ }^{* *} p<0.01$.

\subsection{ON and Sociodemographic and Anthropometric Variables}

The mean DOS score was $17.50 \pm 5.181$ for the Spanish population and 17,49 \pm 5.244 for the Poland sample. Based on the DOS, $89.5 \%$ (770) of the participants did not suffer or have a risk of ON (DOS score $<25), 7.9 \%$ (68) had a risk of ON (DOS score 25-29) and 2.6\% (22) exceeded the preliminary cut of score of ON (DOS score $\geq 30$ ), of which 50\% (11) were Spanish and another 50\% (11) were Polish. Therefore, in the group of Spanish students there was $2.3 \%$ of ON compared to $2.9 \%$ in Polish students $(p>0.05)$.

When comparing the $\mathrm{ON}$ trend in the different groups according to the BMI, no statistically significant differences were found either. However, most of the participants with ON had a normal weight, representing 72.7\% in Spanish and 68.3\% in Polish students $(p>05)$.

Regarding the participants classified as not having ON (838), 8.1\% (68) were classified as at risk for ON according to the DOS questionnaire, of which 60.3\% (41) were Spanish and 39.7\% (27) Polish. When comparing the sociodemographic and anthropometric characteristics in students with risk of ON and without the same, no significant differences were found. Table 3 analyses sociodemographic and anthropometric results among university students without $\mathrm{ON}$ and with those at risk of $\mathrm{ON}$ in each country. 
Table 3. Comparing sociodemographic and anthropometric results among students having no risk of ON and students at risk of developing ON according to the DOS.

\begin{tabular}{|c|c|c|c|c|c|c|c|}
\hline \multirow{2}{*}{\multicolumn{2}{|c|}{ Variables }} & \multicolumn{4}{|c|}{$\begin{array}{c}\text { Spain } \\
(\mathrm{n}=474)\end{array}$} & \multicolumn{2}{|c|}{$\begin{array}{c}\text { Poland } \\
(\mathrm{n}=364)\end{array}$} \\
\hline & & $\begin{array}{c}\text { Having no Risk } \\
\text { of ON }\end{array}$ & $\begin{array}{c}\text { At Risk of } \\
\text { Developing ON }\end{array}$ & $p$-Value & $\begin{array}{c}\text { Having No Risk } \\
\text { of ON }\end{array}$ & $\begin{array}{c}\text { At Risk of } \\
\text { Developing ON }\end{array}$ & $p$-Value \\
\hline \multirow{2}{*}{$\begin{array}{c}\text { Sex } \\
n(\%)\end{array}$} & Male & $\begin{array}{c}190 \\
(43.9 \%) \\
\end{array}$ & $\begin{array}{c}17 \\
(41.5 \%) \\
\end{array}$ & \multirow{2}{*}{$0.766^{\mathrm{a}}$} & $\begin{array}{c}81 \\
(24 \%) \\
\end{array}$ & $\begin{array}{c}5 \\
(18.5 \%) \\
\end{array}$ & \multirow{2}{*}{$0.516^{\mathrm{a}}$} \\
\hline & Female & $\begin{array}{c}243 \\
(56.2 \%)\end{array}$ & $\begin{array}{c}24 \\
(580.5 \%)\end{array}$ & & $\begin{array}{c}256 \\
(76 \%)\end{array}$ & $\begin{array}{c}22 \\
(81.5 \%)\end{array}$ & \\
\hline \multicolumn{2}{|c|}{$\begin{array}{l}\text { Age (years) } \\
\mathrm{M} \pm \mathrm{SD}\end{array}$} & $19.79 \pm 2.22$ & $19.59 \pm 1.76$ & $0.563^{b}$ & $23.07 \pm 3.87$ & $22.41 \pm 2.97$ & $0.384^{b}$ \\
\hline \multicolumn{2}{|c|}{$\begin{array}{c}\mathrm{BMI}\left(\mathrm{kg} / \mathrm{m}^{2}\right) \\
\mathrm{M} \pm \mathrm{SD}\end{array}$} & $22.45 \pm 3.61$ & $22.12 \pm 2.98$ & $0.568^{b}$ & $22.76 \pm 4.80$ & $22.25 \pm 3.49$ & $0.530^{b}$ \\
\hline \multirow{4}{*}{$\begin{array}{c}\text { BMI ranges } \\
\text { n }(\%)\end{array}$} & $<18.5$ & $\begin{array}{c}41 \\
(9.5 \%) \\
\end{array}$ & $\begin{array}{c}5 \\
(12.2 \%) \\
\end{array}$ & \multirow{4}{*}{$0.552^{c}$} & $\begin{array}{c}25 \\
(7.4 \%) \\
\end{array}$ & $\begin{array}{c}3 \\
(11.1 \%) \\
\end{array}$ & \multirow{4}{*}{$0.305^{c}$} \\
\hline & $18.5-24.99$ & $\begin{array}{c}312 \\
(72.1 \%)\end{array}$ & $\begin{array}{c}29 \\
(70.7 \%)\end{array}$ & & $\begin{array}{c}236 \\
(70 \%) \\
\end{array}$ & $\begin{array}{c}20 \\
(74.1 \%)\end{array}$ & \\
\hline & $25-29.99$ & $\begin{array}{c}61 \\
(14.1 \%)\end{array}$ & $\begin{array}{c}6 \\
(14.6 \%)\end{array}$ & & $\begin{array}{c}57 \\
(16.9 \%)\end{array}$ & $\begin{array}{c}3 \\
(11.1 \%)\end{array}$ & \\
\hline & $\geq 30$ & $\begin{array}{c}19 \\
(4.4 \%)\end{array}$ & $\begin{array}{c}1 \\
(2.4 \%)\end{array}$ & & $\begin{array}{c}19 \\
(5.6 \%)\end{array}$ & $\begin{array}{c}1 \\
(3.7 \%)\end{array}$ & \\
\hline
\end{tabular}


When comparing the mean score of each dimension of the EDI between Spanish and Polish university students, a higher mean score was identified in the Spanish sample for drive for thinness $(p<0.01)$ with a lower mean score for the body dissatisfaction $(p<0.01)$, ineffectiveness $(p<0.01)$ and interpersonal distrust $(p<0.01)$ dimensions (Table 4$)$.

Table 4. Cognitive and behavioural features of eating disorder (ED) among students from Spain and Poland.

\begin{tabular}{|c|c|c|c|}
\hline Dimensions & Countries & $\mathrm{M} \pm \mathrm{SD}$ & $p$-Value \\
\hline \multirow{2}{*}{ Drive for thinness } & Spain & $5.08 \pm 5.14$ & \multirow{2}{*}{$0.003 *$} \\
\hline & Poland & $4.05 \pm 4.75$ & \\
\hline \multirow{2}{*}{ Bulimia } & Spain & $2.54 \pm 3.05$ & \multirow{2}{*}{0.845} \\
\hline & Poland & $2.59 \pm 437$ & \\
\hline \multirow{2}{*}{ Body dissatisfaction } & Spain & $5.82 \pm 6.05$ & \multirow{2}{*}{$0.000 *$} \\
\hline & Poland & $7.73 \pm 6.86$ & \\
\hline \multirow{2}{*}{ Ineffectiveness } & Spain & $2.93 \pm 4.02$ & \multirow{2}{*}{$0.000 *$} \\
\hline & Poland & $6.03 \pm 5.08$ & \\
\hline \multirow{2}{*}{ Perfectionism } & Spain & $5.33 \pm 3.77$ & \multirow{2}{*}{0.544} \\
\hline & Poland & $5.16 \pm 4.20$ & \\
\hline \multirow{2}{*}{ Interpersonal distrust } & Spain & $3.00 \pm 3.39$ & \multirow{2}{*}{$0.000 *$} \\
\hline & Poland & $4.87 \pm 4.34$ & \\
\hline \multirow{2}{*}{ Interoceptive awareness } & Spain & $4.55 \pm 4.54$ & \multirow{2}{*}{0.209} \\
\hline & Poland & $5.01 \pm 5.67$ & \\
\hline \multirow{2}{*}{ Maturity fear } & Spain & $6.86 \pm 4.49$ & \multirow{2}{*}{0.994} \\
\hline & Poland & $6.85 \pm 5.22$ & \\
\hline
\end{tabular}

\subsection{Correlations Between $O N$ and ED Symptoms}

Upon analysing the group of participants, a correlation was identified between the DOS scores and several dimensions of the EDI: drive for thinness $(\mathrm{r}=0.170 ; p<0.01)$, bulimia $(\mathrm{r}=0.170 ; p<0.01)$, body dissatisfaction $(\mathrm{r}=0.187 ; p<0.01)$, ineffectiveness $(\mathrm{r}=0.103 ; p<0.01)$, perfectionism $(\mathrm{r}=0.146$; $p<0.01)$ and interoceptive awareness $(\mathrm{r}=0.188, p<0.01)$. However, no correlation was identified with the scores of the interpersonal distrust dimension, nor maturity fear (Table 5). When independently analysing these aspects in the sample of each country, in the Spanish population the same correlations were significant; however, in Poland, the same correlations were found except for the ineffectiveness dimension $(\mathrm{r}=0.075 ; p>0.05)$.

Table 5. Correlation between $\mathrm{ON}$ and ED symptoms in the total sample.

\begin{tabular}{|c|c|c|c|c|c|c|c|c|c|}
\hline & 1 & 2 & 3 & 4 & 5 & 6 & 7 & 8 & 9 \\
\hline $1 . \mathrm{ON}$ & & $0.414^{* *}$ & $0.170^{* *}$ & $0.187^{* *}$ & $0.103^{* *}$ & $0.146^{* *}$ & 0.036 & $0.188^{* *}$ & -0.014 \\
\hline 2. Drive for thinness & & & $0.475^{* *}$ & $0.583^{* *}$ & $0.327^{* *}$ & $0.286^{* *}$ & 0.058 & $0.464^{* *}$ & $0.181^{* *}$ \\
\hline 3. Bulimia & & & & $0.373 * *$ & $0.389 * *$ & $0.365^{* *}$ & $0.114^{* *}$ & $0.607^{* *}$ & $0.195^{* *}$ \\
\hline 4.Body dissatisfaction & & & & & $0.463^{* *}$ & $0.106^{* *}$ & $0.211^{* *}$ & $0.347^{* *}$ & $0.206^{* *}$ \\
\hline 5. Ineffectiveness & & & & & & 0.270 ** & $0.489 * *$ & $0.577^{* *}$ & $0.343^{* *}$ \\
\hline 6. Perfectionism & & & & & & & $0.119^{* *}$ & $0.438^{* *}$ & $0.160 * *$ \\
\hline 7. Interpersonal distrust & & & & & & & & 0.328 ** & $0.179^{* *}$ \\
\hline 8. Interoceptive awareness & & & & & & & & & $0.354^{* *}$ \\
\hline 9. Maturity fear & & & & & & & & & \\
\hline
\end{tabular}




\section{Discussion}

The effect of cultural differences on $\mathrm{ON}$ has been debated in the literature [13]. In addition, the most recently proposed ON definition criteria have already taken cultural aspects into consideration [34]. The present study aimed at investigating ON prevalence among university students in Spain and Poland. Out of the whole sample, ON was prevalent in $2.6 \%$ (50\% of Spanish students and $50 \%$ of Polish students), while 7.9\% exhibited the risk of developing ON (60.3\% of Spanish students and 39.7\% of Polish students). Our results showed that Spanish university students had an ON prevalence rate of $2.3 \%$, whereas the Polish sample had an ON prevalence rate of $2.9 \%$. Since our results were not statistically significant $(p>0.05)$, our first hypothesis was not confirmed. Our results are in contrast to recent findings [40] that showed ON prevalence to be higher among Polish students (66.5\%) compared with Spanish one (18.8\%). It is worth pointing out that those researchers [40] used a different ON self-report questionnaire (ORTO-15) and for this reason it is difficult to compare those results with the findings of the present study. The prevalence of ON among both Spanish and Polish university students is lower than the values observed in previous studies that employed the DOS to investigate German students (3.3\%) [18], Chinese students (7.8\%) [22] and U.S. students (8\%) [21]. Moreover, in our recent studies $10.5 \%$ of Spanish students were classified as having ON [19], while ON was observed in $6.6 \%$ of Polish students [23]. To our knowledge, a total of six studies (published in English) used the DOS among adults from the general population [6,17,47-50] with ON prevalence ranging from $2.3 \%$ [48] to $8.4 \%$ [50]. The prevalence of ON appears to be increasing, and more research is needed to elucidate the cultural and social aspects of disordered eating habits in order to provide culturally appropriate psychological treatment.

The second objective of our study was to compare ED pathology in both samples. Our findings demonstrated that Spanish students reported a greater concern with dieting, preoccupation with weight and entrenchment in an extreme pursuit of thinness than the Polish sample. Meanwhile students in Poland presented higher body dissatisfaction, higher feelings of general insecurity, worthlessness and the feeling of not being in control of their life (ineffectiveness), and a greater sense of alienation and a higher general reluctance to form close relationships (interpersonal distrust) compared to the Spanish sample (H2 was partially confirmed). From these results one may expect that compared to their contemporaries in Spain, students in Poland present a higher risk of developing ED pathology. According to the cultural dimensions [51], some Western countries, like Spain, are likely to be closer to non-Western countries than to other Western countries, like Poland. The Individualism/Collectivism Index classifies Spain as a collectivistic society while Poland as an individualistic culture [51,52]. Collectivist cultures focus on the individual's behaviour for the whole group (cooperative tasks) whereas individualistic societies are characterized by an emphasis on what makes the individual distinct (competitive tasks) [53]. Our findings are in contrast to previous findings [53] from which it was argued that individuals from individualist countries showed a higher drive for thinness and less body dissatisfaction than those from collectivist societies. Nevertheless, our results concur with other studies [54] showing that the thin ideal (directly related to body dissatisfaction and ED symptomatology) is due to Western influence. Based on our results we may expect that collectivist values minimize the expression of ED pathology [54] in our Spanish sample, while abnormal eating patterns might be more influenced by individualism cultural attitudes in our Polish sample.

It is worth pointing out that we used an older version of the EDI [44], which can be considered a limitation of this study. We used the EDI [44] following the recommendation of clinical psychiatrists specialized in eating disorders who recommended the use of an older version of EDI as it was the most used version in the clinical context of the countries where are study took place. Likewise, when we prepared the study, version III of the EDI was not yet available. In addition, in Poland, EDI II and EDI III were not available at the time of our study.

The third objective was to evaluate the relationship between ON and ED symptoms among Spanish and Polish university students. ON was positively linked to cognitive and behavioural features of ED among both samples. Drive for thinness, bulimia, body dissatisfaction, perfectionism, 
interoceptive awareness (in both Spanish and Polish students) and ineffectiveness (in Spanish students) were found to be related to $\mathrm{ON}$ (H3 was confirmed). These results are in line with other studies showing that greater ON symptomatology is associated with greater disordered (pathological) eating among adults from the general population [20,31,32,55], such as body dissatisfaction [47], bulimia [48] or restraint eating, eating concern, weight concern, and shape concern [6]. ON significantly overlapped with ED pathology in both of our samples, suggesting that ON should be consider as disordered eating behaviour closely connected with ED.

\section{Conclusions}

Our findings show that $2.3 \%$ of students in Spain and $2.9 \%$ of students in Poland exceeded the preliminary cut of score of ON, while $8.6 \%$ of the Spanish students and $7.4 \%$ of the Polish sample were at risk of developing ON. Our findings suggest that ON significantly overlapped with ED symptoms, which is in line with recent studies. Healthy eating and healthy lifestyles are viewed as desirable within society. There is also suggestion that Western societies have become orthorexic societies [56], therefore it is difficult to recognize when healthy eating becomes obsessional and problematic [57]. Individual health behavioural patterns that develop during transition from adolescence to adulthood (18-25 years) often persist into later life, influencing individuals' health, that of their partners and/or children [38]. Thus, longitudinal studies are needed to assess how ON develops in a sample of young adults and whether it develops in isolation of or parallel to ED pathology.

Author Contributions: Conceptualization, A.B.-M., M.L.P.-F., M.D.O.-Z. and EF-M; methodology, A.B.-M., E.F.-M. and M.L.P.-F.; software, A.B.-M., M.L.P.-F. and E.F.-M.; validation, A.B.-M., M.L.P.-F. and E.F.-M.; formal analysis, E.F.-M.; investigation, A.B.-M., M.L.P.-F., M.D.O.-Z. and J.M.; resources, A.B.-M., M.L.P.-F. and M.D.O.-Z., EM-F; data curation, E.F.-M.; writing-Original draft preparation, A.B.-M. and E.F.-M.; writing-Review and editing, A.B.-M., M.D.O.-Z., M.L.P.-F., A.S., J.M., E.F.-M.; visualization, A.B.-M., M.D.O.-Z., M.L.P.-F. and E.F.-M.; supervision, A.B.-M., M.D.O.-Z., M.L.P.-F. and E.F.-M.; project administration, A.B.-M., M.L.P.-F., M.D.O.-Z. and E.F.-M.; funding acquisition, A.B.-M. and A.S. All authors have read and agreed to the published version of the manuscript.

Funding: This research received no external funding. The APC was partially funded by the first author (A.B.-M.) and by Medical University of Warsaw, Poland.

Acknowledgments: A.B.-M. acknowledges the financial support by the "Excellence Initiative-Research University" program for years 2020-2026 for University of Wroclaw.

Conflicts of Interest: The authors declare no conflict of interest.

\section{References}

1. Higgs, S.; Thomas, J. Social influences on eating. Curr. Opin. Behav. Sci. 2016, 9, 1-6. [CrossRef]

2. Greville-Harris, M.; Smithson, J.; Karl, A. What are people's experiences of orthorexia nervosa? A qualitative study of online blogs. Eat. Weight Disord. 2020, 25, 1693-1702. [CrossRef]

3. Ambwani, S.; Shippe, M.; Gao, Z.; Austin, S.B. Is cleaneating a healthy or harmful dietary strategy? Perceptions of clean eating and associations with disordered eating among young adults. J. Eat. Disord. 2019, 7, 1-14. [CrossRef]

4. Bratman, S. Health food junkie. Yoga J. 1997, 136, 42-50.

5. Bratman, S.; Knight, D. Health Food Junkies: Overcoming the Obsession with Healthful Eating; Broadway Books: New York, NY, USA, 2000.

6. Strahler, J.; Hermann, A.; Walter, B.; Stark, R. Orthorexia nervosa: A behavioral complex or a psychological condition? J. Behav. Addict. 2018, 7, 1143-1156. [CrossRef]

7. Lopes, R.; Melo, R.; Pereira, B.D. Orthorexia nervosa and comorbid depression successfully treated with mirtazapine: A case report. Eat. Weight Disord. 2020, 25, 163-167. [CrossRef] [PubMed]

8. Belloch, A.; Roncero, M.; Perpiña, C. Obsessional and eating disorder-related intrusive thoughts: Differences andsimilarities within and between individuals vulnerable to OCD or to EDs. Eur. Eat. Disord. Rev. 2016, 24, 446-454. [CrossRef] [PubMed]

9. Dunn, T.M.; Bratman, S.V. On orthorexia nervosa: A review of the literature and proposed diagnostic criteria. Eat. Behav. 2016, 21, 11-17. [CrossRef] [PubMed] 
10. Barrada, J.R.; Roncero, M. Bidimensional Structure of the Orthorexia: Development and Initial Validation of a New Instrument. An. Psicol. 2018, 34, 283-291. [CrossRef]

11. Musolino, C.; Warin, M.; Wade, T.D.; Gilchrist, P. 'Healthy anorexia': The complexity of care in disordered eating. Soc. Sci. Med. 2015, 139, 18-25. [CrossRef]

12. Bóna, E.; Túry, F.; Forgács, A. Evolutionary aspects of a new eating disorder: Orthorexia nervosa in the 21st century. Psychol. Thought 2019, 12, 152-161. [CrossRef]

13. Strahler, J. Sex differences in orthorexic eating behaviors: A systematic review and meta-analytical integration. Nutrition 2019, 67-68, 110534. [CrossRef] [PubMed]

14. Donini, L.; Marsili, D.; Graziani, M.P.; Imbriale, M.; Cannella, C. Orthorexia nervosa: A preliminary study with a proposal for diagnosis and an attempt to measure the dimension of the phenomenon. Eat. Weight Disord. 2004, 9, 151-157. [CrossRef] [PubMed]

15. Barthels, F.; Meyer, F.; Pietrowsky, R. Die Düsseldorfer Orthorexie Skala-Konstruktion und Evaluation eines Fragebogens zur Erfassung ortho-rektischen Ernährungsverhaltens. Z. Klin. Psychol. Psychother. 2015, 44, 97-105. [CrossRef]

16. Barthels, F.; Meyer, F.; Pietrowsky, R. Orthorexic and restrained eating behaviour in vegans, vegetarians, and individuals on a diet. Eat. Weight Disord. 2018, 23, 159-166. [CrossRef]

17. Luck-Sikorski, C.; Jung, F.; Schlosser, K.; Riedel-Heller, S.G. Is orthorexic behavior common in the general public? A large representative study in Germany. Eat. Weight Disord. 2019, 24, 267-273. [CrossRef]

18. Depa, J.; Schweizer, J.; Bekers, S.-K.; Hilzendegen, C.; Stroebele-Benschop, N. Prevalence and predictors of orthorexia nervosa among German students using the 21-item-DOS. Eat. Weight Disord. 2017, 22, 193-199. [CrossRef]

19. Parra-Fernández, M.L.; Onieva-Zafra, M.D.; Fernández-De-Las-Peñas, C.; Fernández-Martínez, E. Adaptation and validation of the Spanish version of the DOS questionnaire for the detection of orthorexic nervosa behavior. PLoS ONE 2019, 14, e0216583. [CrossRef]

20. Parra-Fernández, M.L.; Onieva-Zafra, M.D.; Fernández-Martínez, E.; Abreu-Sánchez, A.; Fernandez-DeLas-Penas, C. Assessing the prevalence of orthorexia nervosa in a sample of university students using two different self-report measures. Int. J. Environ. Res. Public Health 2019, 16, 2459. [CrossRef]

21. Chard, C.A.; Hilzendegen, C.; Barthels, F.; Stroebele-Benschop, N. Psychometric evaluation of the English version of the Düsseldorf Orthorexie Scale (DOS) and the prevalence of orthorexia nervosa among a U.S. student sample. Eat. Weight Disord. 2019, 24, 275-281. [CrossRef]

22. He, J.; Ma, H.; Barthels, F.; Fan, X. Psychometric properties of the Chinese version of the Düsseldorf Orthorexia Scale: Prevalence and demographic correlates of orthorexia nervosa among Chinese university students. Eat. Weigh Disord. 2019, 24, 453-463. [CrossRef] [PubMed]

23. Brytek-Matera, A. The Polish version of the Düsseldorf Orthorexia Scale (PL-DOS) and its comparison with the English version of the DOS (E-DOS). Eat. Weight Disord. 2020, 1-10. [CrossRef] [PubMed]

24. Dell'Osso, L.; Abelli, M.; Carpita, B.; Massimetti, G.; Pini, S.; Rivetti, L.; Gorrasi, F.; Tognetti, R.; Ricca, V.; Carmassi, C. Orthorexia nervosa in a sample of Italian university population. Riv. Psichiatr. 2016, 51, 190-196. [PubMed]

25. Koven, N.S.; Abry, A.W. The clinical basis of orthorexia nervosa: Emerging perspectives. Neuropsychiatr. Dis. Treat. 2015, 11, 385-394. [CrossRef] [PubMed]

26. McComb, S.E.; Mills, J.S. Orthorexia nervosa: A review of psychosocial risk factors. Appetite 2019, 140, 50-75. [CrossRef] [PubMed]

27. Barthels, F.; Barrada, J.R.; Roncero, M. Orthorexia nervosa and healthy orthorexia as new eating styles. Orthorexia nervosa and healthy orthorexia as new eating styles. PLoS ONE 2019, 14, e0219609. [CrossRef]

28. Kummer, A.; Dias, F.M.; Teixeira, A.L. On the concept of orthorexia nervosa. Scand. J. Med. Sci. Sports 2008, 18, 395-397. [CrossRef]

29. Barthels, F.; Meyer, F.; Huber, T.; Pietrowsky, R. Orthorexic eating behaviour as a coping strategy in patients with anorexia nervosa. Eat. Weight Disord. 2017, 22, 269-276. [CrossRef]

30. Missbach, B.; Dunn, T.M.; König, J.S. We need new tools to assess orthorexia nervosa. A commentary on "Prevalence of Orthorexia Nervosa among College Students Based on Bratman's Test and Associated Tendencies.". Appetite 2017, 108, 521-524. [CrossRef] 
31. Mitrofanova, E.; Pummell, E.; Martinelli, L.; Petróczi, A. Does ORTO-15 produce valid data for 'orthorexia nervosa'? A mixed-method examination of participants' interpretations of the fifteen test items. Eat. Weight Disord. 2020, 1-13. [CrossRef]

32. Oberle, C.D.; De Nadai, A.S.; Madrid, A.L. Orthorexia Nervosa Inventory (ONI): Development and validation of a new measure of orthorexic symptomatology. Eat. Weight Disord. 2020, 1-14. [CrossRef] [PubMed]

33. Parra-Fernández, M.L.; Rodríguez-Cano, T.; Onieva-Zafra, M.-D.; Pérez-Haro, M.J.; Casero-Alonso, V.; Fernández-Martínez, E.; Notario-Pacheco, B. Prevalence of orthorexia nervosa in university students and its relationship with psychopathological aspects of eating behaviour disorders. BMC Psychiatry 2018, 18, 364. [CrossRef] [PubMed]

34. Cena, H.; Barthels, F.; Cuzzolaro, M.; Bratman, S.V.; Brytek-Matera, A.; Dunn, T.; Varga, M.; Missbach, B.; Donini, L.M. Definition and diagnostic criteria for orthorexia nervosa: A narrative review of the literature. Eat. Weight Disord. 2019, 24, 209-246. [CrossRef] [PubMed]

35. Brytek-Matera, A.; Donini, L.M.; Krupa, M.; Poggiogalle, E.; Hay, P. Orthorexia nervosa and self-attitudinal aspects of body image in female and male university students. J. Eat. Disord. 2015, 3, 1-8. [CrossRef] [PubMed]

36. Koven, N.S.; Senbonmatsu, R. A neuropsychological evaluation of orthorexia nervosa. Open J. Psychiatry 2013, 3, 214-222. [CrossRef]

37. Scarff, J.R. Orthorexia Nervosa: An obsession with healthy eating. Fed. Pract. 2017, 34, 36-39.

38. Poobalan, A.S.; Aucott, L.S.; Clarke, A.; Smith, W.C.S. Diet behaviour among young people in transition to adulthood (18-25 year olds): A mixed method study. Health Psychol. Behav. Med. 2014, 2, 909-928. [CrossRef]

39. Agopyan, A.; Kenger, E.B.; Kermen, S.; Ulker, M.T.; Uzsoy, M.A.; Yetgin, M.K. The relationship between orthorexia nervosa and body composition in female students of the nutrition and dietetics department. Eat. Weight Disord. 2018, 24, 257-266. [CrossRef]

40. Gramaglia, C.; Gambaro, E.; Delicato, C.; Marchetti, M.; Sarchiapone, M.; Ferrante, D.; Roncero, M.; Perpiñá, C.; Brytek-Matera, A.; Wojtyna, E.; et al. Orthorexia nervosa, eating patterns and personality traits: A cross-cultural comparison of Italian, Polish and Spanish university students. BMC Psychiatry 2019, 19, 235. [CrossRef]

41. Phull, S. The Mediterranean diet: Socio-cultural relevance for contemporary health promotion. Open Public Health J. 2015, 8, 35-40. [CrossRef]

42. Rozin, P.; Remick, A.K.; Fischler, C. Broad themes of difference be-tween French and Americans in attitudes to food and other life do-mains: Personal versus communal values, quantity versus quality, and comforts versus joys. Front. Psychol. 2011, 2, 177. [CrossRef] [PubMed]

43. Vaillancourt, C.; Bédard, A.; Bélanger-Gravel, A.; Provencher, V.; Bégin, C.; Desroches, S.; Lemieux, S. Promoting healthy eating in adults: an evaluation of pleasure-oriented versus health-oriented messages. Curr. Dev. Nutr. 2019, 3. [CrossRef] [PubMed]

44. Garner, D.M.; Olmsted, M.P.; Polivy, J. Development and validation of a multidimensional Eating Disorder Inventory for anorexia nervosa and bulimia. Int. J. Eat. Disord. 1983, 2, 15-34. [CrossRef]

45. Corral, S.; González, M.; Pereña, J.; Seisdedos, N. Adaptación Española del Inventario de Trastornos de la Conducta Alimentaria. EDI-2: Inventario de Trastornos de La Conducta Alimentaria; TEA: Madrid, Spain, 1998; pp. 69-80.

46. Żechowski, C. Polska wersja Kwestionariusza Zaburzeń Odżywiania (EDI)—Adaptacja i normalizacja [Polish Version of Eating Disorder Inventory-Adaptation and normalization]. Psychiatr. Polska 2012, XLII, 179-193.

47. Barthels, F.; Kisser, J.; Pietrowsky, R. Orthorexic eating behavior and body dissatisfaction in a sample of young females. Eat. Weight Disord. 2020, 1-5. [CrossRef]

48. Greetfeld, M.; Hessler-Kaufmann, J.B.; Brandl, B.; Skurk, T.; Holzapfel, C.; Quadflieg, N.; Schlegl, S.; Hauner, H.; Voderholzer, U. Orthorexic tendencies in the general population: Association with demographic data, psychiatric symptoms, and utilization of mental health services. Eat. Weight Disord. 2020, 1-9. [CrossRef]

49. Rudolph, S. The connection between exercise addiction and orthorexia nervosa in German fitness sports. Eat. Weight Disord. 2017, 23, 581-586. [CrossRef]

50. Strahler, J.; Haddad, C.; Salameh, P.; Sacre, H.; Obeid, S.; Hallit, S. Cross-cultural differences in orthorexic eating behaviors: Associations with personality traits. Nutrition 2020, 77, 110811. [CrossRef]

51. Hofstede, G. Culture's Consequences: Comparing Values, Behaviors, Institutions and Organizations across Nations; Sage: Thousand Oaks, CA, USA, 2001. 
52. Fandrejewska, A. Culture and Its Dimensions: Consumer behaviour in Poland and its main export countries. Handel Wewn. 2015, 4, 85-97.

53. Agüera, Z.; Brewin, N.; Chen, J.; Granero, R.; Kang, Q.; Fernandez-Aranda, F.; Arcelus, J. Eating symptomatology and general psychopathology in patients with anorexia nervosa from China, UK and Spain: A cross-cultural study examining the role of social attitudes. PLoS ONE 2017, 12, e0173781. [CrossRef]

54. Swami, V. Cultural influences on body size ideals: Unpacking the impact of Westernization and modernization. Eur. Psychol. 2015, 20, 44-51. [CrossRef]

55. Farchakh, Y.; Hallit, S.; Soufia, M. Association between orthorexia nervosa, eating attitudes and anxiety among medical students in Lebanese universities: Results of a cross-sectional study. Eat. Weight Disord. Stud. Anorex. Bulim. Obes. 2019, 24, 683-691. [CrossRef] [PubMed]

56. Håman, L.; Barker-Ruchti, N.; Patriksson, G.; Lindgren, E.-C. Orthorexia nervosa: An integrative literature review of a lifestyle syndrome. Int. J. Qual. Stud. Health Well Being 2015, 10, 26799. [CrossRef]

57. Vuillier, L.; Robertson, S.; Greville-Harris, M. Orthorexic tendencies are linked with difficulties with emotion identification and regulation. J. Eat. Disord. 2020, 8, 15. [CrossRef] [PubMed]

Publisher's Note: MDPI stays neutral with regard to jurisdictional claims in published maps and institutional affiliations.

(C) 2020 by the authors. Licensee MDPI, Basel, Switzerland. This article is an open access article distributed under the terms and conditions of the Creative Commons Attribution (CC BY) license (http://creativecommons.org/licenses/by/4.0/). 